\title{
The effect of postmastectomy radiotherapy in node-positive triple-negative breast cancer
}

Lei Zhang ${ }^{1,2+}$, Ru Tang ${ }^{1,2+}$, Jia-Peng Deng ${ }^{1,2+}$, Wen-Wen Zhang ${ }^{1,2}$, Huan-Xin Lin ${ }^{1,2}$, San-Gang Wu ${ }^{3^{*}+}$ and Zhen-Yu He $\mathrm{H}^{1,2^{*}+}$ (D)

\begin{abstract}
Background: The value of postmastectomy radiotherapy (PMRT) for pathological node-positive triple-negative breast cancers (TNBC) remains debatable. The aim of this population-based retrospective study was to evaluate the effect of PMRT on survival outcomes in this population.

Methods: Patients diagnosed with stage T1-4N1-N3M0 TNBC between 2010 and 2014 were identified from the Surveillance, Epidemiology, and End Results (SEER) database. We used univariate and multivariate Cox regression hazards method to determine the independent prognostic factors associated with 3-year breast cancer-specific survival (BCSS). The effect of PMRT on 3-year BCSS was analyzed after stratification by pathological staging of groups.
\end{abstract}

Results: Of the 4398 patients included in this study, 2649 (60.2\%) received PMRT. Younger age, black ethnicity, and advanced tumor $(\mathrm{T})$ and nodal $(\mathrm{N})$ stage were the independent predictors associated with PMRT receipt (all $P<$ 0.05). Patients who received PMRT showed better 3-year BCSS $(\mathrm{OR}=0.720,95 \% \mathrm{Cl}=0.642-0.808, P<0.001)$ than those that did not. The effect of PMRT on 3-year BCSS was analyzed after stratification by pathological staging of groups. The results showed that PMRT was associated with better 3-year BCSS in patients with stage T3-4N1 $(P=$ 0.042), T1-4N2 $(P<0.001)$, and T1-4N3 $(P<0.001)$, while comparable 3-year BCSS was found between the PMRT and non-PMRT cohorts with $\mathrm{T} 1-2 \mathrm{~N} 1$ disease $(P=0.191)$.

Conclusions: Radiotherapy achieved better 3-year BCSS in TNBC patients with stage T3-4N1 and T1-4N2-3 disease. However, no survival benefit was found with the addition of PMRT in patients with T1-2N1 TNBC.

Keywords: Breast cancer, Radiotherapy treatment, Prognosis, Survival

\footnotetext{
*Correspondence: unowu12345@hotmail.com; hezhy@sysucc.org.cn

'Lei Zhang, Ru Tang, Jia-Peng Deng, San-Gang Wu and Zhen-Yu He contributed equally to this work.

${ }^{3}$ Department of Radiation Oncology, Cancer Hospital, the First Affiliated Hospital of Xiamen University, Teaching Hospital of Fujian Medical University, Xiamen 361003, China

'Sun Yat-sen University Cancer Center, State Key Laboratory of Oncology in

South China, Collaborative Innovation Center for Cancer Medicine, 651

Dongfeng Road East, Guangzhou 510060, China

Full list of author information is available at the end of the article
}

(C) The Author(s). 2020 Open Access This article is licensed under a Creative Commons Attribution 4.0 International License, which permits use, sharing, adaptation, distribution and reproduction in any medium or format, as long as you give appropriate credit to the original author(s) and the source, provide a link to the Creative Commons licence, and indicate if changes were made. The images or other third party material in this article are included in the article's Creative Commons licence, unless indicated otherwise in a credit line to the material. If material is not included in the article's Creative Commons licence and your intended use is not permitted by statutory regulation or exceeds the permitted use, you will need to obtain permission directly from the copyright holder. To view a copy of this licence, visit http://creativecommons.org/licenses/by/4.0/ The Creative Commons Public Domain Dedication waiver (http://creativecommons.org/publicdomain/zero/1.0/) applies to the data made available in this article, unless otherwise stated in a credit line to the data. 


\section{Background}

Breast cancer is the most common malignant cancer and the primary cause of cancer-related mortality in women. Every year, almost 2,76,000 women are newly diagnosed with breast cancer and about 42,000 women die from it in the United States alone [1]. Enhancing survival outcome by multidisciplinary comprehensive treatment remains the global focus of breast cancer. In current clinical practice, the treatment of breast cancer is based not only on the $\mathrm{T}$ and $\mathrm{N}$ stages of patients but also on the status of estrogen receptor (ER), progesterone receptor, and human epidermal growth factor receptor-2 (HER-2). Breast cancer subtypes based on ER, PR, and HER-2 have been widely used. Triple-negative breast cancer (TNBC) is a subtype characterized by an absence of the ER, PR, and HER-2 status, and accounts for $15 \%$ of all breast cancers [2]. TNBC has a higher risk of early metastasis, local recurrence, and poorer prognosis than other types of breast cancer [3].

Mastectomy is one of the local operations for breast cancer. About one-third of all stage I or II and $68 \%$ of stage III breast cancer patients undergo mastectomy [3]. The National Comprehensive Cancer Network (NCCN) guidelines recommend radiotherapy for patients with more than four positive lymph nodes, while patients with 1-3 lymph nodes are recommended to receive radiotherapy [4]. However, the recommendation of PMRT does not refer to molecular subtypes of breast cancer. A meta-analysis of 22 randomized trials from the Early Breast Cancer Triallists' Collaboration Group (EBCTCG) and other studies showed that radiotherapy could obviously decrease recurrence and mortality risk of TNBC and improve overall survival (OS) of patients with positive lymph nodes [5-7]. The value of PMRT for TNBC patients in different pathological nodal stages has not yet been established. The Danish Breast Cancer Cooperative Group (DBCG) and some other studies have shown that there was no significant survival benefit for TNBC patients with positive lymph nodes from receiving PMRT [8-10]. However, insufficient chemotherapy and axillary lymphadenectomy may have likely limited the power of the analysis. A previously conducted retrospective analysis reported no survival improvement with PMRT in patients with T1-2N1 disease [11]. Collectively, previous studies have shown contradictory results in the investigation of survival according to the status of PMRT receipt in different pathological stages of TNBC.

At present, the recommendation of PMRT is mainly based on the pathological $\mathrm{T}$ and $\mathrm{N}$ stage; the value of PMRT on TNBC patients needs to be further clarified. Therefore, we aimed to identify the effect of PMRT on breast cancer-specific survival (BCSS) in TNBC patients with different pathological nodal stages using the data from the Surveillance, Epidemiology, and End Results (SEER) database.

\section{Methods \\ Study design and patients}

All patient information was collected from the SEER database including 18 cancer registries, which represents $28 \%$ of the population of the United States (https://seer. cancer.gov/). As this database is open-source and informed consent of patients is not required, ethics committee approval by the institutional review board was not needed for this study. We retrospectively reviewed and analyzed the recorded data of eligible patients in terms of their survival time and BCSS. The following inclusion criteria were applied: female sex, year of diagnosis between 2010 and 2014, diagnosed with pathological T14N1-3M0 TNBC, and underwent mastectomy and chemotherapy with or without PMRT. The exclusion criteria were as follows: patients with no information of ethnicity, pathological grade, ER, PR, and HER2 status, and no histology results, and those that received non-external beam radiotherapy or radiotherapy before mastectomy.

\section{Measures}

The tumor sizes and nodal stage were based on the seventh edition of the American Joint Committee on Cancer (AJCC) tumor-staging criteria. We defined the number of months from the date of initial diagnosis to the date of breast cancer-specific death or the date of the last follow-up as BCSS. Age was divided into two groups of $<50$ and $\geq 50$ years. Ethnicity included white, black, and other (American Indian/AK Native, Asian/Pacific Islander). All patients were divided into four groups according to different pathological stages, namely T12N1, T3-4N1, T1-4N2, and T1-4N3 for stratified analysis of the effect of PMRT on TNBC.

\section{Statistical analysis}

The demographic and clinical characteristics of patients were compared using chi-squared test. Prognostic factors of PMRT with odds ratio (OR) and 95\% confidence intervals (95\% CIs) for BCSS were analyzed by univariate and multivariate Cox regression hazard model. Considering that an increase in follow-up time would lead to a decrease in the number of patients being followed-up [12], the number of patients with $>5$-year BCSS in some subgroups enrolled in this study were small $(N<20)$, and some of the selected patients tended to have a short follow-up period which may have led to a bias. Hence, we only used the 3-year BCSS to analyze the prognostic survival value. We considered age, ethnicity, grade, histology, TNM stage, and PMRT as confounding factors for the prognostic analysis; the confounding factors that significantly affected prognosis $(P<0.05)$ were considered as 
prognostic factors. The BCSS comparisons between PMRT and non-PMRT subgroups were analyzed by logrank tests and Kaplan-Meier plots. All potential significant prognostic factors $(P \leq 0.05)$ in the univariate analysis were included in multivariable models to adjust analyses, and multivariate analysis was performed to detect the value of PMRT in terms of BCSS. IBM SPSS version 26.0 (IBM Corp., Armonk, NY, USA) was used for all statistical analyses. $P<0.05$ was considered to indicate statistically significant differences in two-tailed tests.

\section{Results}

\section{Patient characteristics}

A total of 4398 eligible patients were included in this study. All patient characteristics are described in Table 1.
The distribution of histology and grade were similar between the PMRT and non-PMRT groups. Based on the staging groups, pathological T1-2N1 stage constituted a high proportion with $46.7 \%(n=2055)$ patients.

As shown in Table 1, 2649 (60.2\%) patients received PMRT (PMRT group), while the remaining 1749 (39.8\%) did not (non-PMRT group). In the PMRT group, age $<$ 50 years $(41.4 \%$ vs. $35.2 \%)$, black ethnicity $(22.7 \%$ vs. $19.8 \%)$, and $\mathrm{T} 3(21.1 \%$ vs. $15.7 \%)$ and $\mathrm{T} 4(16.4 \%$ vs. $10.2 \%)$ stages showed a higher proportion of acceptance rate, while $\mathrm{T} 1(15.9 \%$ vs. $26.5 \%)$ and $\mathrm{T} 2(46.7 \%$ vs. 47.6\%) stages showed a lower proportion of acceptance rate than in the non-PMRT group. The non-PMRT subgroup presented a significantly higher proportion of pathological N1 stage $(73.1 \%$ vs. $57.9 \%)$ and a lower

Table 1 Patients' baseline characteristics of the study population $(n=4398)$

\begin{tabular}{|c|c|c|c|c|}
\hline Variables & N (\%) & PMRT (\%) & No PMRT (\%) & $P$ value \\
\hline Median follow-up (months) & $41.4(1-83)$ & $41.7(5-83)$ & $40.8(1-83)$ & \\
\hline \multicolumn{5}{|l|}{ Age (years) } \\
\hline$<50$ & $1713(38.9)$ & $1098(41.4)$ & $615(35.2)$ & \multirow[t]{2}{*}{$<0.001$} \\
\hline$\geq 50$ & $2685(61.1)$ & $1551(58.6)$ & $1134(64.8)$ & \\
\hline \multicolumn{5}{|l|}{ Ethnicity } \\
\hline White & 3097 (70.4) & $1848(69.8)$ & $1249(71.4)$ & \multirow[t]{3}{*}{0.044} \\
\hline Black & $948(21.6)$ & $601(22.7)$ & $347(19.8)$ & \\
\hline Other & $353(8.0)$ & $200(7.6)$ & $153(8.7)$ & \\
\hline \multicolumn{5}{|l|}{ Grade } \\
\hline Well-differentiated & $25(0.6)$ & $13(0.5)$ & $12(0.7)$ & \multirow[t]{3}{*}{0.318} \\
\hline Moderately differentiated & $609(13.8)$ & $353(13.3)$ & $256(14.6)$ & \\
\hline Poorly/undifferentiated & 3764 (85.6) & $2283(86.2)$ & $1481(84.7)$ & \\
\hline \multicolumn{5}{|l|}{ Histology } \\
\hline $\mathrm{IDC}^{1}$ & $4036(91.8)$ & $2443(92.2)$ & $1593(91.1)$ & \multirow[t]{3}{*}{0.314} \\
\hline $\mathrm{ILC}^{2}$ & $71(1.6)$ & $43(1.6)$ & $28(1.6)$ & \\
\hline Other & $291(6.6)$ & $163(6.2)$ & $128(7.3)$ & \\
\hline \multicolumn{5}{|l|}{ T3 stage } \\
\hline $\mathrm{T} 1$ & $883(20.1)$ & $420(15.9)$ & $463(26.5)$ & \multirow[t]{4}{*}{$<0.001$} \\
\hline $\mathrm{T} 2$ & $2070(47.1)$ & $1237(46.7)$ & $833(47.6)$ & \\
\hline T3 & $833(18.9)$ & $558(21.1)$ & $275(15.7)$ & \\
\hline T4 & $612(13.9)$ & $434(16.4)$ & $178(10.2)$ & \\
\hline \multicolumn{5}{|l|}{ N4 stage } \\
\hline $\mathrm{N} 1$ & $2812(63.9)$ & $1534(57.9)$ & $1278(73.1)$ & \multirow[t]{3}{*}{$<0.001$} \\
\hline N2 & $937(21.3)$ & $648(24.5)$ & $289(16.5)$ & \\
\hline N3 & $649(14.8)$ & $467(17.6)$ & $182(10.4)$ & \\
\hline \multicolumn{5}{|l|}{ Staging subgroup } \\
\hline $\mathrm{T} 1-2 \mathrm{~N} 1$ & $2055(46.7)$ & 1007 (38.0) & $1048(59.9)$ & \multirow[t]{4}{*}{$<0.001$} \\
\hline T3-4N1 & $757(17.2)$ & $527(19.9)$ & $230(13.2)$ & \\
\hline $\mathrm{T} 1-4 \mathrm{~N} 2$ & $937(21.3)$ & $648(24.5)$ & $289(16.5)$ & \\
\hline T1-4N3 & $649(14.8)$ & $467(17.6)$ & $182(10.4)$ & \\
\hline
\end{tabular}

1. IDC, invasive ductal carcinoma; 2. ILC, invasive lobular carcinoma; 3. T, tumor; 4 . N, nodal 
proportion of pathological N2 (16.5\% vs. $24.5 \%)$ and N3 (10.4\% vs. $17.6 \%)$ stages than the PMRT group. Notable differences were detected in pathological T1-2N1 stage between the PMRT and non-PMRT group $(38.0 \%$ vs. $59.9 \%)$, and pathological T3-4N1, T1-4N2, and T1-4N3 stages were more likely to receive PMRT (19.9\% vs. 13.2, $24.5 \%$ vs. $16.5,17.6 \%$ vs. $10.4 \%$, respectively).

\section{Survival and prognostic analysis}

The predictive factors associated with BCSS were investigated in the cohort of PMRT and non-PMRT groups of TNBC patients. The detailed results are presented in Table 2. The univariate Cox regression analysis revealed age $\geq 50$ years, black ethnicity, and advanced staging groups were associated with worse BCSS in univariate analysis $(P=0.001, P=0.007$ and $P<0.001$, respectively). However, grade and histology types had no statistically significant impact on the BCSS of TNBC (Table 2). Moreover, PMRT was an independent prognostic factor related to superior BCSS according to adjusted multivariate Cox regression analysis $(\mathrm{OR}=0.685,95 \% \mathrm{CI}=$ $0.617-0.760, P<0.001$ ).

Table 2 Univariate and multivariate analysis for the prognostic factors of BCSS

\begin{tabular}{|c|c|c|c|c|c|c|}
\hline \multirow[t]{2}{*}{ Variables } & \multicolumn{3}{|c|}{ Univariate Cox } & \multicolumn{3}{|c|}{ Multivariate Cox } \\
\hline & $\mathrm{OR}^{1}$ & $95 \% \mathrm{Cl}^{2}$ & $P$ value & OR & $95 \% \mathrm{Cl}$ & $P$ value \\
\hline \multicolumn{7}{|l|}{ Age (years) } \\
\hline$<50$ & 1 & & & 1 & & \\
\hline$\geq 50$ & 1.200 & $1.082-1.332$ & 0.001 & 1.121 & $1.009-1.245$ & 0.033 \\
\hline Ethnicity & & & 0.001 & & & 0.010 \\
\hline White & 1 & & & 1 & & \\
\hline Black & 1.177 & $1.046-1.324$ & 0.007 & 1.142 & $1.015-1.285$ & 0.028 \\
\hline Other & 0.808 & $0.660-0.990$ & 0.039 & 0.834 & $0.681-1.022$ & 0.081 \\
\hline Grade & & & 0.085 & & & \\
\hline Well-differentiated & 1 & & & & & \\
\hline Moderately differentiated & 1.101 & $0.543-2.233$ & 0.789 & & & \\
\hline Poorly/undifferentiated & 1.295 & $0.646-2.594$ & 0.467 & & & \\
\hline Histology & & & 0.073 & & & \\
\hline $\mathrm{IDC}^{3}$ & 1 & & & & & \\
\hline $\mathrm{ILC}^{4}$ & 1.147 & $0.789-1.668$ & 0.472 & & & \\
\hline Other & 1.230 & $1.023-1.480$ & 0.028 & & & \\
\hline $\mathrm{T}^{5}$ stage & & & $<0.001$ & & & $<0.001$ \\
\hline $\mathrm{T} 1$ & 1 & & & 1 & & \\
\hline $\mathrm{T} 2$ & 1.516 & $1.289-1.784$ & $<0.001$ & 1.423 & $1.209-1.676$ & $<0.001$ \\
\hline T3 & 2.831 & $2.379-3.370$ & $<0.001$ & 2.201 & $1.791-2.705$ & $<0.001$ \\
\hline $\mathrm{T} 4$ & 4.027 & $3.370-4.812$ & $<0.001$ & 2.900 & $2.363-3.559$ & $<0.001$ \\
\hline $\mathrm{N}^{6}$ stage & & & $<0.001$ & & & $<0.001$ \\
\hline N1 & 1 & & & 1 & & \\
\hline N2 & 1.953 & $1.731-2.204$ & $<0.001$ & 1.753 & $1.553-1.980$ & $<0.001$ \\
\hline N3 & 3.206 & $2.828-3.634$ & $<0.001$ & 2.677 & $2.358-3.039$ & $<0.001$ \\
\hline Staging subgroup & & & $<0.001$ & & & $<0.001$ \\
\hline $\mathrm{T} 1-2 \mathrm{~N} 1$ & 1 & & & 1 & & \\
\hline $\mathrm{T} 3-4 \mathrm{~N} 1$ & 2.394 & $2.066-2.773$ & $<0.001$ & 1.249 & $1.018-1.533$ & 0.033 \\
\hline T1-4N2 & 2.618 & $2.285-3.000$ & $<0.001$ & 1.942 & $1.666-2.263$ & $<0.001$ \\
\hline T1-4N3 & 4.324 & $3.758-4.975$ & $<0.001$ & 3.004 & $2.548-3.542$ & $<0.001$ \\
\hline \multicolumn{7}{|l|}{ PMRT } \\
\hline No PMRT & 1 & & & 1 & & \\
\hline PMRT & 0.931 & $0.841-1.029$ & 0.161 & 0.685 & $0.617-0.760$ & $<0.001$ \\
\hline
\end{tabular}

1. OR odds ratio; 2. Cl confidence interval; 3. IDC invasive ductal carcinoma; 4. ILC invasive lobular carcinoma; $5 . T$ tumor; 6 . $N$ nodal 
With a median follow-up of 41 (range: 1-83) months, a total of 1567 patients $(35.6 \%)$ died; $73.6 \%(n=1154)$ of those patients had breast cancer-related death. The 3year BCSS was $71.2 \%$, and patients in the PMRT group had better 3-year BCSS than those in the non-PMRT group $(P=0.031)$. However, the prognostic survival analysis showed differences among subgroups. Significantly improved 3-year BCSS was found in the subgroups of patients with T1-4N2 $(P<0.001)$ and T1-4N3 $(P<0.001)$ stages who received PMRT, while patients with pathological T3-4N1 stage TNBC with PMRT had comparable 3-year BCSS with patients that did not receive PMRT $(P=0.104)$. In addition, patients with pathological T1-2N1 stage had no significant difference of 3-year BCSS $(P=0.413)$. The Kaplan-Meier survival curves of 3 -year BCSS in overall stages and different staging subgroups are shown in Figs. 1 and 2.

To investigate the effect of PMRT on the 3-year BCSS for TNBC patients in different pathological staging subgroups, multivariate analysis was applied to further analyze the 3-year BCSS stratified by staging subgroups. As shown in Table 3, the results of multivariate analysis indicated that patients who received PMRT in the overall pathological stages had superior 3-year BCSS $(P<0.001)$. Patients with pathological T3-4N1, T1-4N2, and T1-4N3 stages that received PMRT had better survival outcomes than those without PMRT in terms of 3 -year BCSS $(P=0.042$, $P<0.001$, and $P<0.001$, respectively). However, patients with pathological T1-2N1 stage showed comparable 3-year BCSS $(P=0.191)$.

\section{Discussion}

Although the recommendation for TNBC radiotherapy is similar to that for other breast cancer subtypes, the value of PMRT in TNBC patients remains unclear. In this study, we used a population-based study to retrospectively explore the effect of PMRT on 3-year BCSS among TNBC patients with different pathological stages. Our results showed that PMRT could provide significant benefits to 3-year BCSS for TNBC patients in T1-4N2 and T1-4N3 stages; TNBC patients with pathological T3-4N1 stage disease are more suitable for PMRT considering the results of multivariate analysis have more accuracy than the Kaplan-Meier analysis. However, those with T1-2 stage TNBC showed no benefit from PMRT.

The value of PMRT in patients with pathological T1T2N1 stage TNBC disease is still controversial. Previous studies have evaluated the efficacy of PMRT on survival outcomes of TNBC patients. The analysis of Kindts et al. showed that TNBC patients that did not receive PMRT had a worse locoregional recurrence rate (LRR) outcome than those that $\operatorname{did}(\mathrm{HR}=4.45,95 \% \mathrm{CI}=1.26-15.69, P=$

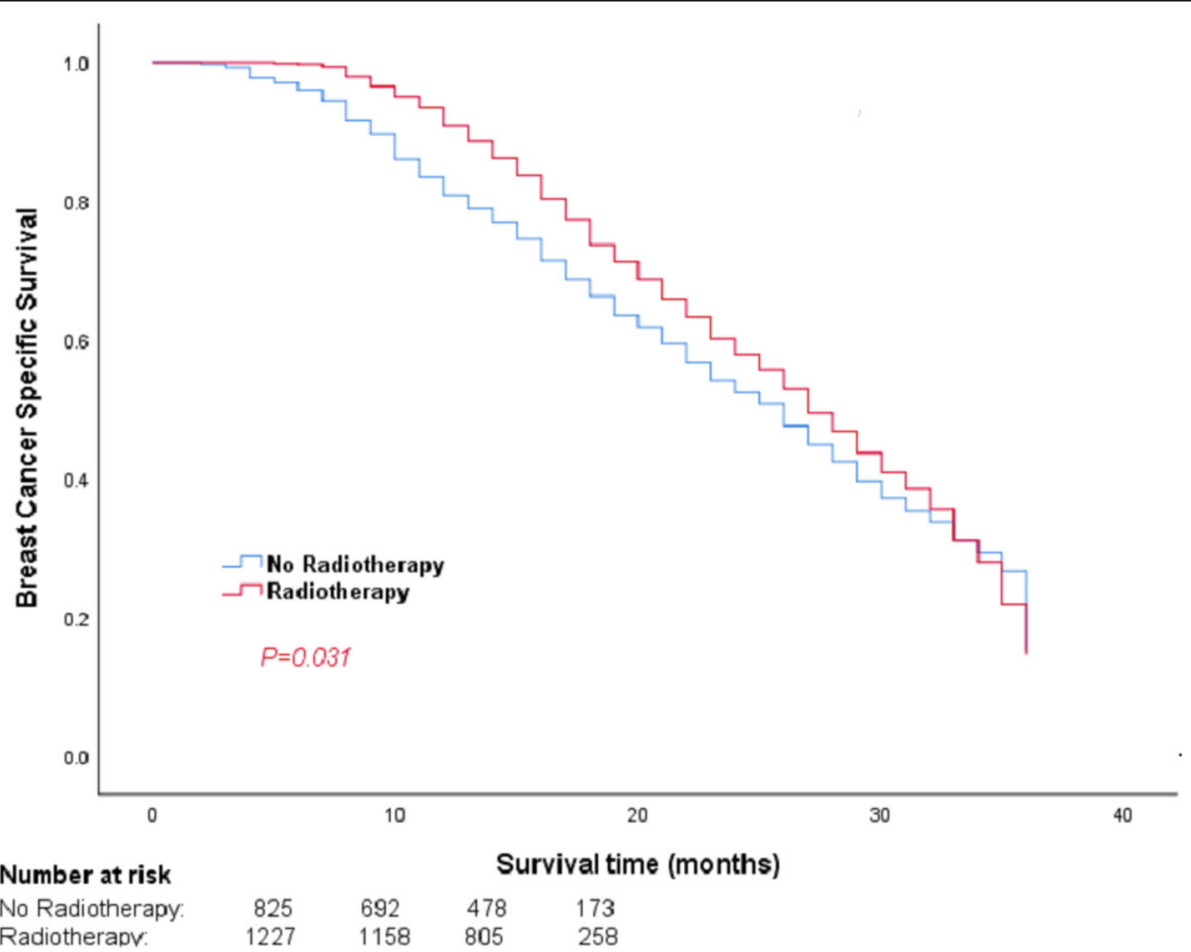

Fig. 1 Kaplan-Meier curves and log-rank tests comparing 3-year BCSS for TNBC patients in the overall pathological staging between PMRT and non-PMRT groups 


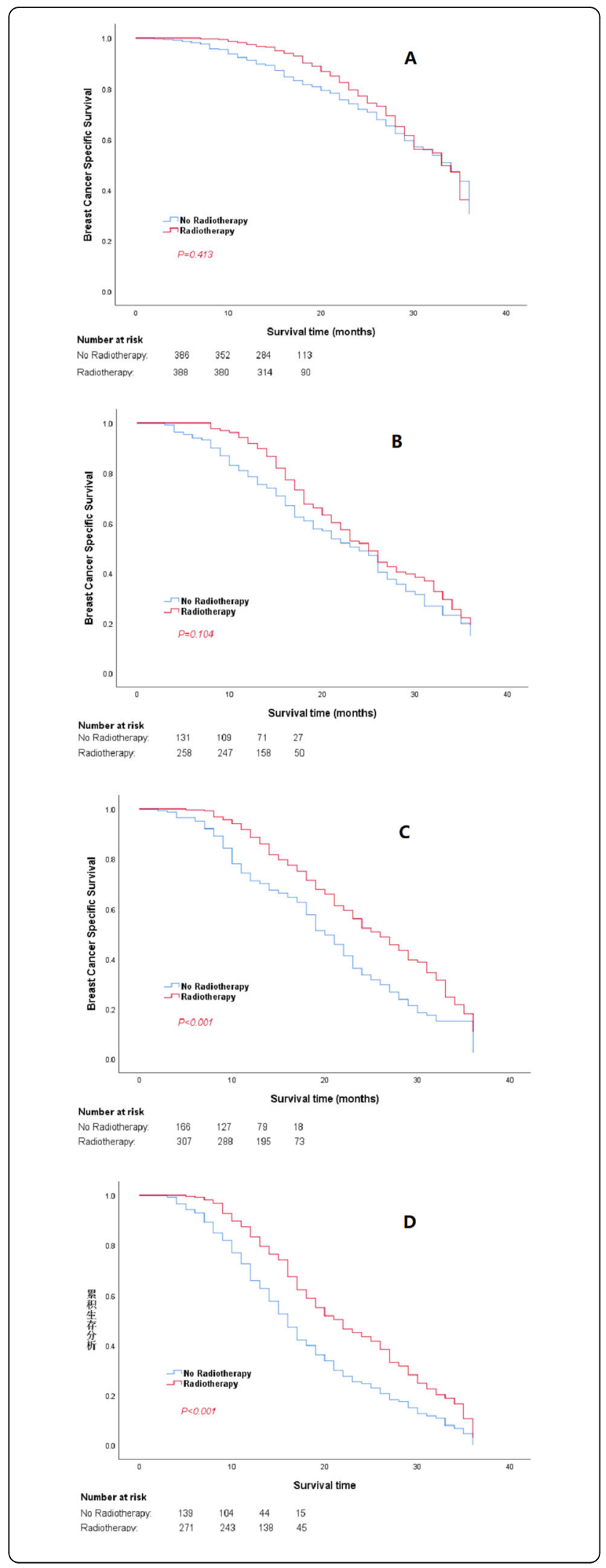

Fig. 2 Kaplan-Meier curves and log-rank tests comparing 3-year BCSS for TNBC patients with different staging subgroups between PMRT and non-PMRT groups. a-d The 3-year BCSS of patients with T1-2N1, T3-4N1, T1-4N2, and T1-4N3 stage TNBC

0.020) [13]. Adjuvant radiotherapy after mastectomy has been shown to reduce the 5 -year LRR by $17 \%$ (6\% vs. $23 \%$ ) and the 15 -year breast cancer mortality by $5.4 \%$ (54.7\% vs. $60.1 \%, P<0.001)$ when compared to those without radiotherapy for node-positive cancer [14]. The American Society of Clinical Oncology (ASCO) recommends that PMRT can be used as a standard essential treatment for patients with $\geq 4$ positive axillary lymph nodes [15]; other researchers have accordingly shown that TNBC patients with positive lymph nodes are also equally eligible for PMRT $[16,17]$. However, the classification criteria of the number of lymph nodes is difficult to implement for some patients. The beneficial impact of PMRT on disease-free survival (DFS) as reported by Chen et al. supports the use of PMRT in pathological T1-T2N1 stage patients despite the absence of a superior locoregional recurrence-free survival (LRFS) outcome [18]. Recent studies showed that pathological T12N1M0 TNBC patients benefit from PMRT with an improved BCSS $(P=0.010)$ [19], while another study in 2004 with 152 TNBC patients showed that pathological T1-2N0-1 stage TNBC without radiotherapy carries a significantly higher risk of LRR $(79.6 \%$ vs. $57.9 \%, P=$ $0.049)$ [20]. The results of the above-mentioned studies were contradictory compared with our outcome, in that pathological T1-2N1M0 stage TNBC patients showed no benefit from PMRT and the 3-year BCSS rates were comparable between the PMRT and non-PMRT subgroups $(P=0.191)$. The inherent selection biases in patient selection and treatment, lack of information about some clinical characteristics, small sample size, and the long interval with respect to the present study are some

Table 3 Multivariate Cox proportional hazard analysis evaluating the effect of PMRT stratified by staging subgroups

\begin{tabular}{llll}
\hline $\begin{array}{l}\text { Staging } \\
\text { subgroups } \\
\text { (non-PMRT }\end{array}$ & 3-year BCSS & 95\% Cl (OR) & $\boldsymbol{P}^{a}$ value \\
\cline { 2 - 4 } $\begin{array}{l}\text { vs. PMRT) } \\
\text { Overall stage }\end{array}$ & 0.720 & $0.642-0.808$ & $<0.001$ \\
T1-2N1 & 0.861 & $0.689-1.078$ & 0.191 \\
T3-4N1 & 0.765 & $0.591-0.991$ & 0.042 \\
T1-4N2 & 0.622 & $0.501-0.774$ & $<0.001$ \\
T1-4N3 & 0.630 & $0.505-0.787$ & $<0.001$ \\
\hline
\end{tabular}

$O R$ odds ratio; 2 . $C l$ confidence interval; $3 . P^{a}$ value was adjusted by a multivariate Cox proportional hazard regression model including age, ethnicity, pathological $\mathrm{T}$ and $\mathrm{N}$ stage, and radiotherapy 
of the limitations that likely contributed to the inconsistent results.

However, some studies showed that pathological N1 stage TNBC patients do not require PMRT as a necessary treatment $[9,21]$.. PMRT was associated with an increase in radiation toxicities such as lymphedema, cardiotoxicity, and pneumonitis [2224]. The consensus of the St. Gallen Breast Cancer Conference showed that more than $64 \%$ experts opposed the recommendation of introducing PMRT as a routine treatment for patients with pathological T1-2N1M0 stage breast cancer, and instead recommended considering the omission of PMRT in pathological T1-2 patients with 1-3 positive lymph nodes [25]. Although there are no exact statistics about the efficacy of PMRT in patients with pathological T1-2N1M0 stage TNBC, most clinicians seemed to indicate that PMRT provided no significant benefit for patients with pathological T1-2N1 stage disease in overall breast cancer types. In a retrospective multicenter analysis, Kim et al. found that T1-2N1 stage patients who received PMRT had no obvious improvement of DFS and OS because of the malignant biological features and radio-resistance of TNBC cells [26]. Bhoo-Pathy et al's study showed that PMRT was not associated with improved survival in T1-2N0-1 TNBC patients, but showed better survival outcome in T3-4N2-3 TNBC patients [27]. The results of these studies are consistent with our outcome. Mastectomy and chemotherapy have been associated with low risk of LRR in TNBC patients with 1-3 positive lymph nodes, and TNBC patients benefit more from chemotherapy when PMRT alone does not provide better curative efficacy [28]. Neo-adjuvant chemotherapy is an important treatment modality in TNBC; however, its effect on PMRT is still controversial and more prospective trials are needed to validate the results $[29,30]$. Patients with 1-3 positive lymph nodes who received modern taxane-based chemotherapy had excellent locoregional control; thus, the use of PMRT in patients with 1-3 positive nodes should be tailored to individual patient risks [31]. As seen in our study, PMRT provided no benefits for patients with T1$2 \mathrm{~N} 1$ stage TNBC. We reasonably assumed that TNBC patients with pathological $\mathrm{T} 1-2 \mathrm{~N} 1$ stage show relatively good disease control by undergoing mastectomy plus chemotherapy. PMRT is not universally administered in pathological $\mathrm{T} 1-2 \mathrm{~N} 1$ stage TNBC and should be chosen as a personal requirement especially for patients with higher nodal stages or high-risk biology [32], such as those aged $\geq 50$ years and of black ethnicity as analyzed in our multivariate Cox hazard analysis. Therefore, the risk factors in
TNBC patients with pathological T1-2N1 stage who consider receiving PMRT should be fully considered by clinicians.

According to the results of our study, an increasing trend of 3-year BCSS benefit was reflected based on the Kaplan-Meier plots. The patients were stratified for survival analysis by pathological $\mathrm{T}$ and $\mathrm{N}$ stages for more solid elucidation. Our results validated the data that PMRT is a strong predictive factor of better BCSS for patients with pathological T3-4N1, T1-4N2, and T14N3 stage TNBC. Both Kaplan-Meier and multivariate analysis showed that patients with T1-4N2 and T1-4N3 stages who received PMRT had better 3-year BCSS, which was in line with previous studies that reported that additional PMRT for patients with high-risk (stage T3-4 and/or N2-3) TNBC showed superior outcomes in the LRFS and DFS $[18,33]$. Patients with pathological T3-4N1 stage TNBC showed contradictory results of 3year BCSS in both the Kaplan-Meier and multivariate analyses. However, considering that the Kaplan-Meier analysis is a univariate analysis and that the effect of some other factors on PMRT may be omitted, we believe that the results of multivariate analysis are more reliable in order to improve the long-term BCSS. The ASCO recommends considering the need for PMRT for patients with T1-2N1 stage disease by evaluating the risk factors [15]. The NCCN breast cancer guidelines recommend that patients with pathological T3-4 primary tumors or N2-3 axillary lymph nodes after mastectomy should undergo PMRT as a standard adjuvant therapy [4].

Our study has some limitations. First, this is a retrospective analysis from the SEER database rather than a prospective, randomized controlled trial. Therefore, we cannot clarify the reasons for patients choosing PMRT; moreover, the inherent selection biases could undermine the validity of our analysis. Second, some information about patients' complications, systemic chemotherapy regimens (adjuvant and neo-adjuvant), and the situation of nodal irradiation were absent from the SEER database, which may have led to unconvincing results. At the same time, some of the selected patients in this study had a short follow-up period, and the data might be skewed by the number of patients with relatively short follow-up. Therefore, we did not consider overall survival as an analytical indicator. Thus, we were unable to evaluate the influence of PMRT on LRR of TNBC patients and balance the different possible effects of chemotherapy with PMRT. LRR is an important indicator to evaluate the efficacy of radiotherapy; hence, missing information on LRR, distant metastasis, dose of radiotherapy, and target area are also limitations of the study. Last, SEER may underestimate the reporting rate of radiotherapy. Hence, a randomized controlled clinical study is needed to provide more evidence and a 
scientific basis to guide clinical treatment. We are currently looking forward to the results of the Selective Use of Postoperative Radiotherapy after Mastectomy trial, where patients with pathological T1-2N1 stage disease were separated randomly into radiotherapy or nonradiotherapy subgroups [34].

\section{Conclusions}

Radiotherapy is an important treatment modality for TNBC patients. The study has provided evidence that patients with pathological T3-4N1 and T1-4N2-3 stage TNBC benefit from PMRT with a better 3-year BCSS; however, PMRT is not beneficial for those with pathological T1-2N1 stage TNBC. These patients should decide whether to undergo PMRT in light of other highrisk factors. Further prospective studies are recommended to elucidate the benefit of PMRT in TNBC patients and provide a strong evidence base for patient selection.

\section{Abbreviations}

PMRT: Postmastectomy radiotherapy; TNBC: Triple negative breast cancer; SEER: The SurveillanceEpidemiology, and End Results database; BCSS: Breast cancer-specific survival; T: Tumor; N: Nodal; EBCTCG: The Early Breast Cancer Triallists' Collaboration Group; OS: Overall survival; DBCG: The Danish Breast Cancer Cooperative Group; AJCC: the American Joint Committee on Cancer; OR: Odds ratio; Cl: Confidence interval; LRR: Locoregional recurrence rate; ASCO: The American Society of Clinical Oncology; DFS: Disease-free survival; LRFS: Locoregional recurrence-free survival; ALNs: Axillary lymph nodes

\section{Acknowledgements}

None.

\section{Authors' contributions}

Conception, design, and acquisition of data: L.Z., R.T., J.P.D, W.W.Z., H.X.L., Z.Y.H., S.G.W. Data collection, analysis, and interpretation: L.Z., R.T., J.P.D. Manuscript draft and revision: All authors. All authors read and approved the final manuscript.

\section{Funding}

This study was supported by the National Natural Science Foundation of China (No. 81872459, 81803050) and the Natural Science Foundation of Guangdong Province (No. 2018A030313666).

\section{Availability of data and materials}

The authors declare that all datasets generated and analyzed are available in the SEER database (https://seer.cancer.gov/).

\section{Ethics approval and consent to participate}

As this database is open-source and informed consent of patients is not required, ethics committee approval by the institutional review board was not needed for this study.

\section{Consent for publication}

Not applicable.

\section{Competing interests}

The authors declare that they have no competing interests.

\section{Author details}

${ }^{1}$ Sun Yat-sen University Cancer Center, State Key Laboratory of Oncology in South China, Collaborative Innovation Center for Cancer Medicine, 651 Dongfeng Road East, Guangzhou 510060, China. ${ }^{2}$ Department of Radiotherapy, Sun Yat-sen University Cancer Center, 651 Dongfeng Road East, Guangzhou 510060, People's Republic of China. ${ }^{3}$ Department of
Radiation Oncology, Cancer Hospital, the First Affiliated Hospital of Xiamen University, Teaching Hospital of Fujian Medical University, Xiamen 361003, China

Received: 18 July 2020 Accepted: 15 November 2020

Published online: 25 November 2020

\section{References}

1. Siegel RL, Miller KD, Jemal A. Cancer statistics, 2020. CA Cancer J Clin. 2020; 70(1):7-30.

2. Sharma P. Update on the treatment of early-stage triple-negative breast Cancer. Curr Treat Options in Oncol. 2018;19(5):22.

3. DeSantis CE, Ma J, Gaudet MM, Newman LA, Miller KD, Goding Sauer A Jemal A, Siegel RL. Breast cancer statistics, 2019. CA Cancer J Clin. 2019; 69(6):438-51.

4. Gradishar WJ, Anderson BO, Balassanian R, Blair SL, Burstein HJ, Cyr A, Elias AD, Farrar WB, Forero A, Giordano SH, et al. Breast Cancer, version 4.2017, NCCN clinical practice guidelines in oncology. J Natl Compr Cancer Netw. 2018;16(3):310-20.

5. Kindts I, Buelens $P$, Laenen A, Van Limbergen $E$, Janssen $H$, Wildiers $H$, Weltens $C$. Omitting radiation therapy in women with triple-negative breast cancer leads to worse breast cancer-specific survival. Breast. 2017;32:18-25.

6. El-Sabawi B, Ho AL, Sosin M, Patel KM. Patient-centered outcomes of breast reconstruction in the setting of post-mastectomy radiotherapy: a comprehensive review of the literature. J Plast Reconstr Aesthet Surg. 2017; 70(6):768-80.

7. EBCTCG. Effect of radiotherapy after mastectomy and axillary surgery on 10year recurrence and 20-year breast cancer mortality: meta-analysis of individual patient data for 8135 women in 22 randomised trials. Lancet. 2014;383(9935):2127-35.

8. Kyndi M, Sorensen FB, Knudsen H, Overgaard M, Nielsen HM, Overgaard J. Danish breast Cancer cooperative G: estrogen receptor, progesterone receptor, HER-2, and response to postmastectomy radiotherapy in high-risk breast cancer: the Danish breast Cancer cooperative group. J Clin Oncol. 2008;26(9):1419-26.

9. Nordenskjöld AE, Fohlin H, Albertsson P, Arnesson LG, Chamalidou C, Einbeigi Z, Holmberg E, Nordenskjöld B, Karlsson P. No clear effect of postoperative radiotherapy on survival of breast cancer patients with one to three positive nodes: a population-based study. Ann Oncol. 2015;26(6): 1149-54.

10. Jagsi R. Progress and controversies: radiation therapy for invasive breast cancer. CA Cancer J Clin. 2014;64(2):135-52.

11. Li F-Y, Lian C-L, Lei J, Wang J, Hua L, He Z-Y, Wu S-G. Real-world impact of postmastectomy radiotherapy in T1-2 breast cancer with one to three positive lymph nodes. Ann Transl Med. 2020;8(7):489.

12. Gill A, Gosain R, Bhandari S, Gosain R, Gill G, Abraham J, Miller K. "lost to follow-up" among adult Cancer survivors. Am J Clin Oncol. 2018;41(10): 1024-7

13. Kindts I, Buelens $P$, Laenen A, Limbergen EV, Janssen $H$, Wildiers $H$, Weltens C. Omitting radiation therapy in women with triple-negative breast cancer leads to worse breast cancer-specific surviva. Breast J. 2017:32:18-25.

14. (EBCTCG) EBCTCG. Effects of radiotherapy and of differences in the extent of surgery for early breast cancer on local recurrence and 15-year survival: an overview of the randomised trials. Lancet. 2005;366(9503):2087-106.

15. Recht A, Comen EA, Fine RE, Fleming GF, Hardenbergh PH, Ho AY, Hudis CA, Hwang ES, Kirshner JJ, Morrow M, et al. Postmastectomy radiotherapy: an American Society of Clinical Oncology, American Society for Radiation Oncology, and Society of Surgical Oncology focused guideline update. Ann Surg Oncol. 2016:24(1):38-51.

16. Zhang J, Wang X-X, Lian J-Y, Song C-G. Effect of postmastectomy radiotherapy on triple-negative breast cancer with T1-2 and 1-3 positive axillary lymph nodes: a population-based study using the SEER 18 database. Oncotarget. 2019;10:5245-52

17. Chen L, Zhang J, Chen J, Liu L, Liang L, Shangguan Z, Wang D. Postoperative radiotherapy is beneficial for $\mathrm{T} 1 / \mathrm{T} 2$ triple negative breast cancer patients with four or more positive lymph nodes. Oncotarget. 2017:8: 42917-25.

18. Chen $X$, Yu X, Chen J, Yang Z, Shao Z, Zhang Z, Guo X, Feng Y. Radiotherapy can improve the disease-free survival rate in triple-negative 
breast cancer patients with T1-T2 disease and one to three positive lymph nodes after mastectomy. Oncologist. 2013;18(2):141-7.

19. Wang X, Xu Y, Guo S, Zhang J, Abe M, Tan H, Wang S, Chen P, Zong L. T12N1MO triple-negative breast cancer patients from the SEER database showed potential benefit from post-mastectomy radiotherapy. Oncol Lett. 2020;19(1):735-44.

20. Dragun AE, Pan J, Rai SN, Kruse B, Jain D. Locoregional recurrence in patients with triple-negative breast Cancer. Am J Clin Oncol. 2011;34(3):231-7.

21. Nagao T, Kinoshita T, Tamura N, Hojo T, Morota M, Kagami Y. Locoregional recurrence risk factors in breast cancer patients with positive axillary lymph nodes and the impact of postmastectomy radiotherapy. Int J Clin Oncol. 2011;18(1):54-61.

22. Waks AG, Winer EP. Breast Cancer treatment: a review. JAMA. 2019;321(3): 288-300.

23. Cheng YJ, Nie XY, Ji CC, Lin XX, Liu LJ, Chen XM, Yao H, Wu SH. Long-Term Cardiovascular Risk After Radiotherapy in Women With Breast Cancer. J Am Heart Assoc. 2017:6(5). PMID 28529208.

24. Zhu Q, Kirova YM, Cao L, Arsene-Henry A, Chen J. Cardiotoxicity associated with radiotherapy in breast cancer: a questionbased review with current literatures. Cancer Treat Rev. 2018;68:9-15.

25. Balic M, Thomssen C, Würstlein R, Gnant M, Harbeck N. St. Gallen/Vienna 2019: A Brief Summary of the Consensus Discussion on the Optimal Primary Breast Cancer Treatment. Breast Care. 2019;14:103-10.

26. Kim Y-J, Park W, Ha B, Park B, Joo J, Kim TH, Park IH, Lee KS, Lee ES, Shin KH, et al. Postmastectomy radiotherapy in patients with PT1-2N1 breast Cancer treated with Taxane-based chemotherapy: a retrospective multicenter analysis (KROG 1418). Cancer Res Treat. 2017;49. PMID 28052654.

27. Bhoo-Pathy N, Verkooijen HM, Wong F-Y, Pignol J-P, Kwong A, Tan E-Y, Taib NA, Nei W-L, Ho G-F, Tan B, et al. Prognostic role of adjuvant radiotherapy in triple-negative breast cancer: a historical cohort study. Int I Cancer. 2015; 137:2504-12.

28. Wang J, Shi M, Ling R, Xia Y, Luo S, Fu X, Xiao F, Li J, Long X, Wang J, et al. Adjuvant chemotherapy and radiotherapy in triple-negative breast carcinoma: a prospective randomized controlled multi-center trial. Radiother Oncol. 2011;100(2):200-4.

29. Akyurek S. GY: role of Pstmastectomy radiation therapy after Neoadjuvant chemotherapy in locally advanced breast cancer. Exp Oncol. 2013;35:267-71.

30. De Felice F, Osti MF, De Sanctis V, Musio D, Tombolini V. Critical decisionmaking in radiotherapy for early stage breast cancer in a neo-adjuvant treatment era. Expert Rev Anticancer Ther. 2017;17(5):481-5.

31. Zeidan YH, Habib JG, Ameye L, Paesmans M, de Azambuja E, Gelber RD, Campbell I, Nordenskjold B, Gutierez J, Anderson M, et al. Postmastectomy radiation therapy in women with T1-T2 tumors and 1 to 3 positive lymph nodes: analysis of the breast international group 02-98 trial. Int J Radiat Oncol Biol Phys. 2018;101(2):316-24.

32. Waks AG, Winer EP. Breast Cancer Treatment. JAMA. 2019:321(3). PMID 30667505.

33. Yao Y, Chu Y, Xu B, Hu Q, Song Q. Radiotherapy after surgery has significant survival benefits for patients with triple-negative breast cancer. Cancer Med. 2019:8(2):554-63.

34. Kunkler IH, Canneyy P. Tienhovenz GV, Russellx NS, group obotMEB-STM: elucidating the role of Chest Wall irradiation in 'intermediate-risk' breast Cancer: the MRC/EORTC SUPREMO trial. Clin Oncol. 2008;20:31-4.

\section{Publisher's Note}

Springer Nature remains neutral with regard to jurisdictional claims in published maps and institutional affiliations.

Ready to submit your research? Choose BMC and benefit from:

- fast, convenient online submission

- thorough peer review by experienced researchers in your field

- rapid publication on acceptance

- support for research data, including large and complex data types

- gold Open Access which fosters wider collaboration and increased citations

- maximum visibility for your research: over $100 \mathrm{M}$ website views per year

At BMC, research is always in progress.

Learn more biomedcentral.com/submissions 